fisheries, and the potential role of upwelling in the drawdown of atmospheric $\mathrm{CO}_{2}$, further understanding of climate feedbacks in upwelling regions and the ecological and socioeconomic repercussions is imperative.

This study also demonstrates that marine sediment cores do provide levels of information comparable to more traditional high-resolution proxies. Future studies focused on decadal-resolution marine sediment cores have the very real potential to contribute invaluable data on ocean and climate processes.

\section{Note}

The data are archived at the Publishing Network for Geoscientific and Environmental Data public digital library (www.pangaea.de/).

\section{References}

Anderson, D.M., Overpeck, J.T. and Gupta, A.K., 2002: Increase in the Asian Southwest Monsoon during the past four centuries, Science, 297: 596-599.

Bakun, A., 1990: Global climate change and intensification of coastal ocean upwelling, Science, 247: 198-201.

Goes, J.I., Thoppil, P.G., do R Gomes, H. and Fasullo, J.T., 2005: Warming of the Eurasian Landmass is making the Arabian Sea more productive, Science, 308: 545-547.

Harley, C.D., Hughes, A.R., Hultgren, K.M., Miner, B.G., Sorte, C.J.B., Thornber, C.S., Rodriguez, L.F., Tomanek, L. and Williams, S.L., 2006. The impacts of climate change in coastal marine systems, Ecology Letters, 9: 228-241, doi:10.1111/j.1461-0248 2005.00871.x.
McGregor, H.V., Dima, M., Fischer, H.W. and Mulitza, S., 2007: Rapid 20th-Century increase in coastal upwelling off northwest Africa Science, 315: 637-639, doi: 10.1126/science.1134839.

For full references please consult:

www.pages-igbp.org/products/newsletter/ref2007_2.htm

\section{2}

\title{
UK IGBP - Paleo and modern perspectives on global change: A personal summary
} London, UK, 27 June 2007

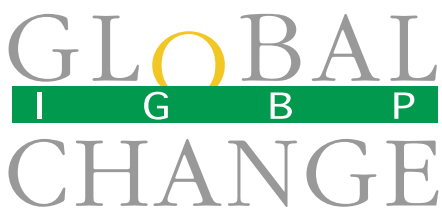

\section{SANDY HARRISON}

School of Geographical Sciences, Bristol University, UK; Sandy.Harrison@bristol.ac.uk

The need to understand the mechanisms and processes of climate and environmental change is a fundamental scientific challenge with profound practical implications. The components of the Earth System respond to perturbations on very different timescales: the atmosphere reacts in hours to years, natural ecosystems over years to centuries, the ocean over centuries to millenia, and the cryosphere over millennia and longer. Thus, it is important to examine climate and environmental changes in the perspective offered by the geological record of the past million years or so, as well as in the recent or historical period, in order to assess (and potentially improve) our ability to quantify anthropogenic effects.

Questions that arise from the paleorecord are modeling foci in several of the IGBP core projects. Explaining the tightly controlled upper and lower limits on atmospheric trace gas concentrations through glacial-interglacial cycles as shown by the ice core record is a focus in IGAC, iLEAPS and SOLAS. Understanding how ecosystem structure and function are affected by changes in atmospheric composition, biogeochemical cycles and climate is a focus in GLP and IMBER. However, paleodata gathering and analysis activities (necessary to compare with modeling results) fall within the domain of PAGES. This structure, combined with the generally limited communication between modelers and observationalists and between scientists working on modern and paleo timescales, may limit progress towards an integrated understanding of global change.
It was with these concerns in mind that the UK IGBP Committee organized a oneday meeting at the Royal Society in June this year to explore commonalities between modern and paleo-perspectives on global change. Speakers from each of the core projects, and members of the PAGES community, were invited to address the common themes of: biodiversity, ecosystem structure and functioning; the regulation of ocean productivity; ocean fertilization and the biological pump; fluxes to the coastal ocean-changing land-surface conditions and human interactions; and natural regulation of atmospheric oxidizing capacity.

One theme that emerged is the scarcity of high-quality data on key processes. In the ocean, for example, there are large uncertainties in estimates of primary production and vanishingly few measurements of respiration outside the Atlantic. Estimates of iron solubility in the ocean range over several orders of magnitude; different measures of export production sometimes yield opposite signals of change between glacial and interglacial states. On land, assessments of contemporary rates of biodiversity loss are heavily biased by sampling of charismatic species, while natural migration rates are poorly constrained. There are few experiments quantifying $\mathrm{CO}_{2}$ fertilization outside the temperate forest zone; there is very limited understanding of the differential resilience of plants, insects and mammals to environmental change. However, the lack of data to address key questions may sometimes be more apparent than real: a major limitation is the availability of data in appropriate formats and centralized facilities. Networking and synthesis activities sponsored by PAGES and the Paleoclimate Modeling Intercomparison Project (PMIP) have shown that there are many hundreds more individual paleo records than are generally known to the paleo-modeling community. Similarly, GLOPNET (Wright et al., 2004) and the IGBP Fast-Track Initiative on Plant Functional Classification are demonstrating that there is an untapped wealth of measurements that could be used to analyze plant and ecosystem processes when brought together in a global database.

A second emerging theme was that multiple data sources can offer valuable complementary perspectives but that this synergy is often not exploited. The existence of multiple paleo proxies for a given process or variable has often been interpreted as increased "uncertainty" in paleoclimate reconstructions, largely because of the focus on statistical rather than process-based interpretation of the records. Paleo-observations can challenge our understanding of modern processes in surprising ways: the record of past changes in vegetation patterns, for example, indicates that migration rates can be fast, and that plant species have been extremely resilient in the face of large and rapid climate changes such as occurred in the North Atlantic region during the deglaciation. Sedimentary records from estuarine environments indicate much 
larger variability in water and sediment fluxes to the coastal oceans than revealed by the limited observations available from monitored rivers. The challenge is to use long-term observations to inform analyses of potential future changes and to help define the questions worth asking.

A third emerging theme was the need for a more sophisticated approach to modeling. Models are necessarily simplifications of the real world; they can lead to erroneous conclusions. For example, to the extent that ocean biology depends on ocean circulation, conclusions about the role of changes in the biological pump for glacial-interglacial $\mathrm{CO}_{2}$ changes are hampered by limitations in ocean general circulation models. However, the creation of ever more complex models incorporating a multiplicity of feedbacks creates its own problems-e.g., the diagnosis of the causes of simulated changes - and is not a panacea. One implication is that the paleocommunity should move away from the concept of using their data for model evaluation towards the idea that models and data should be used together to explore hypotheses concerning the causes of phenomena. This should be achieved by collaboration involving people fully informed about the strengths and weaknesses of both models and data sets.

A clear overall message from the meeting was the need for a sustained dialog between the modeling and observational communities, and a dialog that bridges the divide between modern and paleo timescales. A sustained dialog cannot be achieved entirely through ad hoc meetings. Efforts such as ELME (European Lifestyles and Marine Ecosystems) and LOIS (NERC Land-Ocean Interactions Study) suggest that integration within a project framework is a potentially effective solution. Similarly, a closer integration between PAGES and the other IGBP projects in the planning and implementation of activities would be highly desirable. This could be assisted through Fast-Track Initiatives, and/or explicit cross-project activities. A second message is that while we need to continue efforts to monitor the Earth System and to make new measurements of key processes, we also need to exploit the full potential of existing observations through global syntheses and analyses. Organizing, archiving and disseminating these syntheses and analyses appropriately will require a clearer definition of intellectual property rights in the research framework.

Finally, it was generally accepted that process-based modeling is the key to making sense of observations. One aspect of this is developing the tools that will enable us to take the "proxy" out of paleo records, i.e., models that explicitly simulate the relative abundance of different groups of organisms or isotopic tracers. "Taking the models to the data" is not a new idea, but now, with the rapid development of process-based models for land and marine ecosystems and for many isotopic tracers, the tools are at hand to make it a practical reality.

\section{Dusted off the PAGES bookshelf Paleoclimate, Global Change and the Future}

**All chapters and figures are now available digitally for free download**

\section{www.pages-igbp.org/products/}

\section{Editors: K. Alverson, R. Bradley and T. Pedersen 2003, Springer-Verlag, Heidelberg, Germany, (out of print)}

This book synthesizes the last decade of research into past global changes in the Earth System. It aims to provide a quantitative understanding of the Earth's environment in the geologically recent past, and to define the envelope of natural environmental variability, against which anthropogenic impacts on the Earth System may be assessed.

\section{Content}

Preface: (K. Alverson, R. Bradley, T. Pedersen)

1: The societal relevance of paleoenvironmental research

(F. Oldfield, K. Alverson)

2: The Late Quaternary history of atmospheric trace gases and aerosols

(D. Raynaud, T. Blunier, Y. Ono, R.J. Delmas)

3: The history of climate dynamics in the Late Quaternary

(L. Labeyrie, J. Cole, K. Alverson, T. Stocker)

4: The Late Quaternary history of biogeochemical cycling of carbon

(T.F. Pedersen, R. Francois, L. Francois, K. Alverson, J. McManus)

5: Terrestrial biosphere dynamics in the climate system: past and future

(J. Overpeck, C. Whitlock, B. Huntley)

6: The climate of the last millenium

(R.S. Bradley, K.R. Briffa, J. Cole, M.K. Hughes, T.J. Osborn)

7: The rold of human activities in past environmental change

(F. Oldfield, J. Dearing)

8: Challenges of a changing Earth: past perspectives, future concerns

(R.S. Bradley, K. Alverson, T.F. Pedersen)

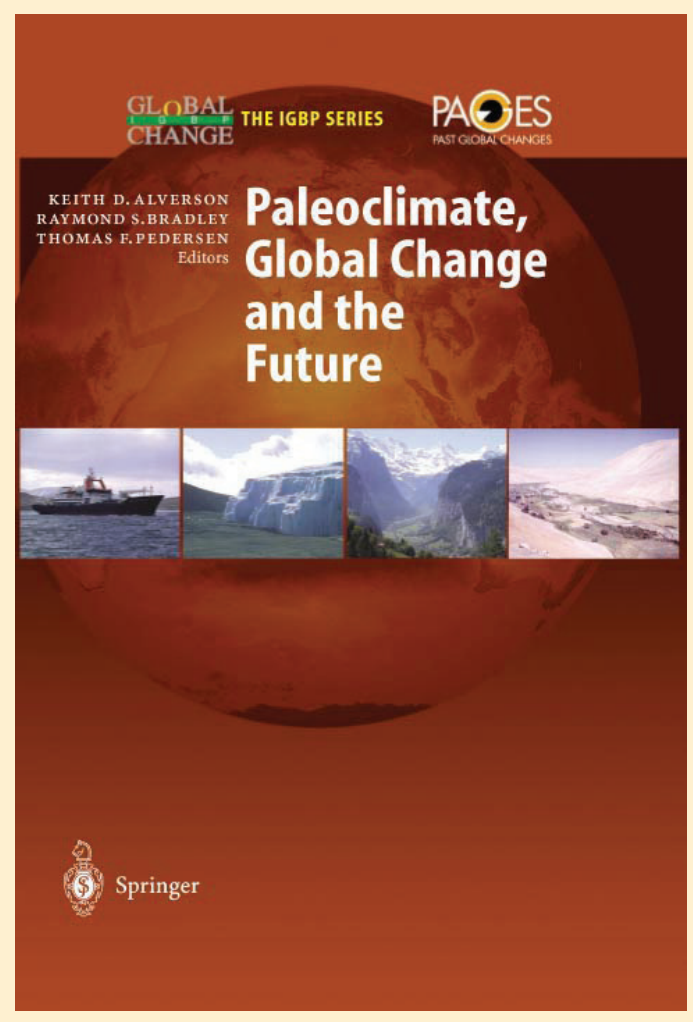

